\title{
TRANSTORNOS DEPRESSIVOS E CAPITALISMO CONTEMPORÂNEO
}

\author{
Elton Corbanezi*
}

\begin{abstract}
O objetivo do artigo é mostrar como a evolução da nosologia psiquiátrica da depressão pode se relacionar com determinadas demandas do capitalismo contemporâneo. Primeiro, investigamos as concepções de transtornos depressivos desde a terceira edição do Manual Diagnóstico e Estatístico de Transtornos Mentais (DSM), que instaurou o paradigma psiquiátrico vigente até nossos dias, enfocando, especialmente, as duas últimas versões (DSM-IV-TR e DSM-5). Ao lado da Classificação Internacional de Doenças da OMS, as edições recentes do Manual constituem os principais sistemas classificatórios de psiquiatria, orientando a prática clínica e embasando conceitualmente a ideia atual de epidemia depressiva. Em seguida, fazemos ver como a teoria econômica do capital humano, elaborada por economistas neoliberais da Escola de Chicago, se converte em valor social que, aceito e disseminado amplamente, orienta a conduta de vida dos indivíduos tanto em sociedades liberais avançadas quanto nas terceiro-mundistas. Pretendemos sustentar, assim, que a sistemática ramificação e a flexibilização dos transtornos depressivos, as quais estabelecem como patológicas formas tênues de sofrimento, correspondem à lógica de intensificação do desempenho de determinadas capacidades individuais imprescindíveis ao capitalismo contemporâneo.

Palavras-chave: Transtornos depressivos. Capitalismo contemporâneo. Capital humano. Conduta de vida. Epidemia depressiva.
\end{abstract}

\section{INTRODUÇÃO}

Diferentemente das duas versões anteriores, a terceira edição do Manual Diagnóstico e Estatístico de Transtornos Mentais (DSM-III), da Associação Psiquiátrica Americana (APA), apresenta um novo paradigma psiquiátrico que altera radicalmente o modo como a psiquiatria ocidental compreende os transtornos depressivos. Se antes, sob a influência psicodinâmica, a depressão era considerada de acordo com a etiologia e o contexto dos sintomas e se baseava na dicotomia neurose e psicose e (ou) reativa e endógena, a abordagem inaugurada pelo DSM-III em 1980 pretende descontextualizar os sintomas e desconsiderar a etiologia, de forma a padronizar a prática diagnóstica e a produzir dados cientificamente confiáveis. Para a nova clínica sindrômica e descritiva, não importa mais - ao menos em tese - se os transtornos depressivos são endógenos, exógenos ou psicogênicos.

* Universidade Federal de Mato Grosso (UFMT). Instituto de Ciências Humanas e Sociais. Departamento de Sociologia e Ciência Política.

Av. Fernando Correa da Costa, 2367, Boa Esperança. Cep: 78060-900. Cuiabá - Mato Grosso - Brasil.

eltonrcorbanezi@gmail.com
Como se sabe, a causalidade biológica da depressão ainda não é manifesta, dado que a síndrome prescinde, até nossos dias, de marcadores biológicos efetivos. Ou seja, apesar da existência de indicadores biológicos não específicos - tais como anormalidades do sono encontradas por meio de polissonografia, desregulação de sistemas de neurotransmissores, alterações de neuropeptídios, de hormônios e de fluxo sanguíneo cerebral -, as versões mais recentes do DSM asseguram que semelhantes evidências são insuficientes para constituir a fisiopatologia específica da depressão (APA, [2000] 2002, p. 351-352; APA, 2013, p. 165). A despeito da assertiva e da pretensa eliminação de pressupostos etiológicos que constituem a inovação clínica e metodológica fundamental estabelecida pelo DSM-III, a predominante ação terapêutica e neuroquímica de antidepressivos visa, especialmente, a recobrir o déficit de neurotransmissores, que operam, então, como causalidade latente, independentemente das circunstâncias desencadeadoras do transtorno, as quais os DSM-I e II julgavam necessário compreender. Depreende-se dessa prática, portanto, a prevalência da concepção atual de 
depressão como desequilíbrio neuroquímico, proveniente do que se convencionou designar "prova terapêutica", que consiste em aferir a causalidade da patologia a partir do efeito de antidepressivos como os Inibidores Seletivos de Recaptação de Serotonina (ISRS), os Tricíclicos e os Inibidores de Monoamina Oxidase (IMAO). Isto é, se a eficácia do mecanismo de ação de antidepressivos reside no aumento de disponibilidade de serotonina, noradrenalina e dopamina para receptores pós-sinápticos, é o déficit de tais neurotransmissores - especialmente da serotonina - que constitui, por decorrência, a causalidade da síndrome; daí a ideia corrente de que são os antidepressivos que definem a depressão. ${ }^{1}$ Associada ao desenvolvimento da psicofarmacologia, a psiquiatria contemporânea - pretensamente ateórica e descritiva - apresenta, pois, o seguinte paradoxo: ao mesmo tempo em que registra a ausência de marcadores biológicos em diversos transtornos mentais, como se lê na versão mais recente do manual, o DSM-5 (APA, 2013, p. 21), sua prática clínica crê na existência deles. Diante disso, deve-se notar, de partida, como a "abordagem ateórica" da depressão preconizada desde o DSM-III implica uma prática clínica e terapêutica que indica a parcialidade da concepção: em vez de problema existencial, a depressão se $\stackrel{\infty}{a}$ reduz a uma disfunção neuroquímica.

ํ. Expostos os fundamentos básicos a par$\sum_{1}^{\circ}$ tir dos quais a psiquiatria apreende a depressão e considerando a relativa continuidade de sua racionalidade nas sucessivas versões do Manual, analisamos, em seguida, como os transtornos depressivos são apresentados e descritos desde o DSM-III, destacando, especialmente, as duas últimas versões do Manual (DSM-IV-TR e DSM-5), que orientam a prática clínica e embasam os dados epidemiológicos atuais. No entanto, é preciso assinalar que, ao lado da vigência da Classificação Internacional de Doenças, a CID-10 (OMS, 1993), é a quar-

${ }^{1}$ A esse respeito, ver o conceito de "petite biologie", a partir do qual Pignarre (2003) indica a função epistemológica do psicofármaco diante da ausência de marcadores biológicos da depressão. ta versão do manual da APA que fundamenta conceitualmente a afirmação oficial da OMS (2001, p. 53-58) de que a depressão constitui, em nossos dias, a principal carga de incapacidade e se tornará, até 2020, a segunda maior carga patológica mundial, atrás apenas das doenças isquêmicas cardíacas. ${ }^{2}$ Não obstante a observação, examinamos igualmente as mudanças significativas em relação aos transtornos depressivos na última versão do manual, o DSM-5, que funciona como vetor de desenvolvimento da classificação psiquiátrica contemporânea. Procedendo assim, pretendemos mostrar, por fim, de que maneira a evolução da nosologia psiquiátrica da depressão - ou seja, o estabelecimento de diversos subtipos do transtorno - pode se relacionar com as demandas do capitalismo contemporâneo, para o qual, a despeito de sua variedade de formas em diferentes contextos de desenvolvimento, a depressão parece constituir-se efetivamente como um problema de ordem epidêmica.

\section{AS CONCEPÇÕES PSIQUIÁTRICAS DE TRANSTORNOS DEPRESSIVOS}

No DSM-III, os transtornos depressivos constituem três categorias diagnósticas agrupadas na classe "Transtornos afetivos" (Affective disorders), a saber: "depressão maior", "transtorno distímico", ou - como ao lado desta expressão figura entre parênteses - "neurose depressiva", e "depressão atípica", que se torna, a partir do DSM-III-R, "transtorno depressivo sem outra especificação” (S.O.E.). Na versão revisada de 1987, o DSM-III-R, a classe que reúne os transtornos depressivos recebe a designação “mais descritiva” (APA, [1987] 1989, p. 441) de "Transtornos de humor" (Mood disorders), a qual agrupa ainda os transtornos bipolares e perma2 Uma pesquisa epidemiológica transnacional, realizada em conjunto com a OMS e publicada em 2011, corrobora a informação de que a depressão, segundo a concepção do DSM-IV, é uma das principais causas de incapacidade em todo o mundo, como revelam os dados relativos a países de alta, média e baixa renda (Bromet et al., 2011). Atualmente, a OMS estima que 350 milhões de pessoas sofram de depressão no mundo (Marcus et al., 2012). 
nece até o DSM-IV-TR, publicado em 2000. No tocante aos transtornos depressivos, tal classe apresenta as mencionadas categorias diagnósticas: "depressão maior", "distimia" e "transtorno depressivo S.O.E.”. É apenas no DSM-5 que os transtornos depressivos e os transtornos bipolares são separados, tornando-se classes distintas com suas respectivas nomeações e com categorias diagnósticas próprias.

No DSM-IV-TR, que é a quarta edição revisada do Manual, a classe "Transtornos do humor" envolve as seguintes perturbações: transtornos depressivos, transtornos bipolares e dois transtornos baseados na etiologia, sendo um devido a uma condição médica geral (e. g.: depressão decorrente de hipotireoidismo) e outro induzido por substância (e. g.: droga de abuso, medicamento, toxina). A fim de mostrar como o Manual territorializa diferentes experiências no conceito extenso de depressão, analisemos as seguintes classificações: "transtorno depressivo maior", "distimia” e "transtorno depressivo sem outra especificação", no qual se incluem as categorias indicadas para estudos adicionais, tais como "transtorno disfórico pré-menstrual”, "transtorno depressivo menor" e "transtorno depressivo breve recorrente".

A categoria principal é o transtorno depressivo maior, cujas características são humor deprimido e (ou) anedonia, somados a uma lista de sintomas como alterações no apetite ou peso, insônia ou hipersonia, agitação ou retardo psicomotor, fadiga ou diminuição da energia, sentimentos de inutilidade ou culpa, dificuldades para pensar, concentrar-se ou tomar decisões, pensamentos recorrentes sobre morte ou ideação suicida, planos ou tentativas de suicídio. Para a consumação diagnóstica, é preciso que o paciente apresente, no mínimo, um dos dois sintomas nucleares - humor deprimido e (ou) anedonia) - mais quatro sintomas adicionais durante pelo menos duas semanas (critério A). O DSM-IV-TR apresenta ainda outros quatro critérios diagnósticos, entre os quais destacamos dois que são inéditos em relação ao DSM-III-R. ${ }^{3}$ O primeiro (critério C) é que os sintomas devem causar "sofrimento clinicamente significativo ou prejuízo no funcionamento social ou ocupacional ou em outras áreas importantes do indivíduo" (APA, [2000] 2002, p. 355). Como se vê, tal critério estabelece absoluta conformidade com a função operacional do conceito de transtorno mental, cuja definição é o sofrimento e a disfunção ou prejuízo na capacidade de desempenho nas relações ocupacionais, sociais, interpessoais e familiares. De acordo com Horwitz e Wakefield (2010), esse critério de transtorno é especialmente problemático no caso da depressão, uma vez que tanto o sofrimento quanto o prejuízo funcional, social ou ocupacional podem decorrer de situações críticas de perdas às quais o indivíduo reage com tristeza intensa, fadiga, insônia, entre outros sintomas depressivos que, contextualizados, não poderiam ser considerados patológicos. Outra adição significativa em relação ao DSM-III-R é o critério E que inviabiliza o diagnóstico, caso os sintomas sejam provenientes de luto no período de dois meses. Embora o DSM-III-R já ressaltasse que “... a perturbação não é uma reação normal à morte de uma pessoa amada..." (APA, [1987] 1989, p. 238), essa versão não especificava a duração do luto normal, como estabelece a edição subsequente.

A polêmica em torno da exclusão do critério relativo ao luto no DSM-5 é digna de nota. Não obstante a premissa do atual paradigma psiquiátrico de desconsiderar, em parte significativa dos casos, a etiologia e o contexto dos sintomas, a quarta versão do manual orienta o clínico a julgar como normais os sintomas decorrentes de luto, “... a menos que estejam associados com acentuado prejuízo funcional ou incluam preocupação mórbida com desvalia, ideação suicida, sintomas psicóticos ou retardo psicomotor ...” (APA, [2000] 2002, p.

${ }^{3}$ Os outros dois critérios (B e D) postulam o seguinte, respectivamente: os sintomas não satisfazem os critérios para um episódio misto, que configura um tipo de transtorno bipolar, e os sintomas não decorrem de efeitos fisiológicos diretos de substâncias ou de uma condição médica geral. 
351). Como se sabe, o DSM-5 eliminou esse único critério de exclusão diagnóstica em contextos de perda, reduzindo, assim, a normalidade dos sintomas presentes no luto para apenas duas semanas, que é a duração limite para que sintomas depressivos ainda não configurem um transtorno psiquiátrico. Todavia, em vez de uma simples exclusão, como o fato se disseminou através de diferentes meios de comunicação, o DSM-5 apresenta duas passagens que sugerem cautela clínica na avaliação dos sintomas, de modo a não confundi-los com reação de tristeza intensa normal. A primeira observação, que figura no corpo do texto, menciona os contextos de perda (loss) para além da morte da seguinte maneira:

Respostas a perdas [loss] significativas (e.g., mortes [bereavement], ruína financeira, perdas [losses] advindas de um desastre natural, uma deficiência ou doença médica grave) podem incluir os sentimentos de tristeza intensa, ruminação sobre a perda, insônia, falta de apetite e perda de peso observados no Critério A e que podem se parecer com um episódio depressivo. Embora tais sintomas possam ser compreendidos ou considerados apropriados à perda, a presença de um episódio depressivo maior, em adição à resposta normal a uma perda significativa, deve ser também considerada cuidadosamente. Essa inevitável decisão requer o exercício de julgamento clínico baseado na história do indivíduo e nas normas culturais para a expressão do sofrimento no

${ }^{4}$ As traduções para o português são de minha responsabilidade.
2013), travando uma batalha insistente contra a exclusão do critério relativo ao luto no DSM5, que permaneceu aberto para escrutínio público durante sua preparação. De acordo com o psiquiatra que presidiu a Força-Tarefa do DSM-IV, nem mesmo os melhores clínicos treinados seriam capazes, fazendo uso do bom senso diagnóstico, de distinguir sintomas normais de luto de depressão amena, como defendem os responsáveis pelo DSM-5 (Frances, 2013). Mobilizando críticos como Wakefield, Cacciatore e Friedman, o psiquiatra estadunidense chama a atenção para a ausência de evidências científicas que sustentem validamente a redução da duração do luto normal, ao mesmo tempo em que denuncia o interesse da indústria farmacêutica, pronta a "educar" clínicos e pacientes potenciais a propósito de que a duração acima de quatorze dias de sintomas comuns de luto constitua, confiavelmente, um episódio depressivo maior. ${ }^{5}$

Sob o risco de reduzir a credibilidade científica e médica do Manual, uma decisão como essa fortalece, no entanto, o prognóstico sombrio da OMS, dado o aumento expressivo da quantidade de diagnósticos falsos positivos que o novo conceito de depressão deve ocasionar. ${ }^{6}$ Porém a fabricação da ideia de epidemia depressiva pode resultar não apenas do excesso de diagnósticos potencialmente incorretos que provêm, no contexto clínico, do afrouxamento dos já muito soltos critérios diagnósticos que definem a depressão. ${ }^{7}$ Tal ideia

${ }^{5}$ Nossos grifos pretendem chamar a atenção para a debatida polêmica a respeito da primazia, estabelecida desde o DSM-III, para a confiabilidade diagnóstica - isto é, sua padronização cientificamente necessária -, em detrimento da validade diagnóstica, que consiste em compreender a realidade clínica e a natureza da estrutura e da realidade patológica subjacentes (cf. Angell, 2011; Dunker, 2013; Ehrenberg, 1998; Gori, 2011; Horwitz; Wakefield, 2010; Insel, 2013; Pereira, 2013; Serpa Júnior, 1997).

${ }^{6}$ De acordo com Horwitz e Wakefield (2010, p. 45-48), o luto constitui o único caso de reação à perda em que o DSM-IV considera corretamente o contexto dos sintomas depressivos. Com base em estudos estatísticos diversos, os autores mostram como a inexistência de tal cláusula, que desaparece efetivamente no DSM-5, implicaria, de modo incontornável, uma altíssima incidência de depressão.

${ }^{7}$ Não sem ironia, afirma Frances (2013): "Em sua tentativa zelosa de nunca perder nenhum paciente possível, o DSM-5 endossa ainda mais o afrouxamento do que já são os critérios muito soltos para depressão - portanto, etique- 
alarmante é também apresentada e divulgada por meio de pesquisas epidemiológicas, cujos questionários são comumente aplicados por leigos, treinados para desconsiderar o contexto dos sintomas, que serão depois contabilizados impessoalmente e de forma computadorizada, como mostram Horwitz e Wakefield (2010, p. 147-169), para os quais o boom da depressão, a partir dos anos 1970 e 1980, se deve, sobretudo, ao modo como a síndrome passou a ser concebida e diagnosticada para além do contexto hospitalar. Ora, do ponto de vista lógico, não há dúvida de que a mudança nas determinações do conceito de depressão modifica sua extensão; ${ }^{8}$ ainda que haja uma nota advertindo cautela médica e bom senso no julgamento clínico, a dignidade humana do luto normal se torna, então, refém de diferentes Simões Bacamartes que podem interpretá-la segundo seus próprios interesses e perspectivas. ${ }^{9}$

Outra categoria diagnóstica que integra os transtornos depressivos é a distimia. Apresentada inicialmente no DSM-III, essa perturbação se caracteriza pela cronicidade e menor intensidade e quantidade de sintomas depressivos. Para satisfazer os critérios diagnósticos da distimia segundo o DSM-IV, o indivíduo deve apresentar humor deprimido persistentemente, durante dois anos no mínimo, e mais pelo menos dois sintomas de uma lista que contém alterações no apetite, no sono, fadiga ou baixa de energia, baixa autoestima, baixa concentração, dificuldade para tomar decisões e sentimentos de desesperança (Critérios A e

tando erroneamente o luto e ferindo potencialmente muitos milhões de enlutados". Em vez de cuidar de centenas de milhões de enlutados, insta o psiquiatra, o campo da saúde mental deveria voltar sua atenção àqueles que, de fato, necessitam de cuidados médicos psiquiátricos.

${ }^{8}$ Questionando o estatuto de doença atribuído à depressão, Fédida (2002, p. 179-180) sustenta que o conceito se apresenta como uma "quase noção", sem consistência nosográfica, vagamente descritivo e possivelmente em vias de extinção. Para o psicanalista francês, a ideia de "quase noção" se deve à grande extensão prática do conceito de depressão e seu inevitável efeito de banalização, que produz, assim, a epidemia depressiva.

${ }^{9}$ Como se sabe, Simão Bacamarte é o médico psiquiatra protagonista de $O$ Alienista, irônico conto de Machado de Assis (2006).
B)..$^{10}$ Além disso, é necessário que, durante os dois anos, os sintomas não tenham remitido em mais do que dois meses, nem satisfaçam os critérios diagnósticos de transtorno depressivo maior, que seria especificado, então, como "crônico" (Critérios C e D). Da mesma forma que os critérios para transtorno depressivo maior, não deve haver sintomas de episódio misto, maníaco, hipomaníaco ou de outros transtornos, tampouco devem ser eles atribuídos a efeito fisiológico direto de qualquer substância ou devidos a uma condição médica geral (Critérios E, F e G). Por último, o DSM-IV adverte igualmente que os sintomas devem causar sofrimento clinicamente significativo ou prejuízo no funcionamento em alguma área importante da vida do indivíduo.

No DSM-5, a distimia é acoplada ao transtorno depressivo maior crônico, adquirindo ambas as terminologias uma mesma designação classificatória, a saber, transtorno depressivo persistente (APA, 2013, p. 168-171). Em virtude dessa unificação, uma das exigências da nova categoria diagnóstica é apresentar os critérios para transtorno depressivo maior por dois anos, continuamente. Desse modo, a categoria encerra duas formas de depressão crônica, tanto com maior quanto com menor quantidade de sintomas.

Valendo-se da distimia como exemplo privilegiado para evidenciar a extensão da ação da psiquiatria biológica no tecido social, Henning (2000) chama a atenção para um aspecto controverso da categoria: sua proximidade com os transtornos da personalidade, que constituem o eixo II da avaliação multiaxial vigente no DSM-IV. ${ }^{11}$ É que, insidiosa, a dis-

${ }^{10}$ Registre-se que, no DSM-III (APA, 1980, p. 220-223), a distimia se caracterizava pela presença de humor deprimido e (ou) anedonia e mais três sintomas de uma lista de treze. A redução para apenas dois sintomas adicionais, estabelecida pelo DSM-III-R e mantida no DSM-IV, pode indicar a tendência gradativa de o Manual capturar experiências cada vez mais tênues de sofrimento, patologizando-as.

11 A categoria "transtorno da personalidade depressiva" consta no apêndice em que o DSM-IV indica categorias que solicitam estudos adicionais para a incorporação na nosologia oficial. Em diagnóstico diferencial da categoria, afirma-se a utilidade controversa da distinção entre transtorno da personalidade depressiva e distimia (cf. APA, 
timia apresenta normalmente início precoce, curso crônico e intensidade menor, fazendo-se confundir, assim, com o modo de existência do indivíduo, que, muitas vezes, não se reconhece doente. ${ }^{12}$ É o que o próprio manual da APA afirma diante de um possível caso de distimia: "Quando o Transtorno Distímico tem uma duração de muitos anos, fica difícil distinguir a perturbação do humor do funcionamento 'habitual' da pessoa" (APA, [2000] 2002, p. 375).

Desde o DSM-III, porém, o transtorno distímico integra o eixo I, que é constituído por síndromes clínicas que os indivíduos possuem, embora elas não os classifiquem. ${ }^{13}$ Ressaltando essa ambiguidade intrínseca ao transtorno, Henning (2000, p. 127-129) mostra como a distimia constitui um caso patente do que Pignarre (2003) evidencia igualmente em sua tese: tal perturbação corrobora a ideia de que os psicofármacos determinam não apenas a invenção de algumas categorias diagnósticas como também o lugar que elas devem ocupar na nosologia psiquiátrica oficial. É que a distimia, mostra a pesquisadora a partir de uma análise crítica do livro Distimia: do mau humor ao mal do humor (Moreno et al., 2010), tornou-se uma síndrome clínica pertencente ao eixo I, sobretudo em função da experiência bem sucedida com antidepressivos. ${ }^{14}$ Relativi-

[2000] 2002, p. 737). É provável que a semelhança entre as $\checkmark$ duas categorias justifique o desaparecimento da primeira $\dot{\circ}$ no DSM-5, como se a nova nomenclatura "transtorno de$\underset{\$}{\infty}$ pressivo persistente" a englobasse.

${ }^{12}$ Sabe-se que uma característica fundamental para dis$\Sigma$ tinguir o normal e o patológico em psiquiatria, quando a

กิ razão do indivíduo não está comprometida, é o autodiag-

ๆ nóstico, já que o indivíduo experimenta por conta própria

เ่ $\mathrm{c}$ que define o conceito de transtorno mental, a saber, o m sofrimento e a disfunção.

غ. ${ }^{\dot{2}}{ }^{13} \mathrm{Na}$ introdução da terceira e da quarta edição, o DSM $\infty$ adverte que se destina a classificar os transtornos que as ¿ pessoas apresentam, e não o que elas são (APA, 1980, p. 6;

- $\mathrm{APA}, 1989$, p. XXIII; APA, [1994] 2000, p. 21; APA[2000]

๓ 2002, p. 28). Por essa razão, o Manual utiliza expressões

$>$ perifrásticas como "um indivíduo com esquizofrenia", em

ธิ substituição a "um esquizofrênico", por exemplo, a fim

శ్శ de fortalecer o processo de desestigmatização das pessoas que sofrem com transtornos mentais.

œ ${ }^{14}$ Eis o que os psiquiatras Nardi e Cordás (apud Henning, 2000, p. 129) escrevem na versão de 1997 do livro em

U questão: "A melhor definição fenomenológica, genética e

$\circ$ a resposta terapêutica aos antidepressivos e estabilizado-

res do humor foram decisivos para a mudança taxonômi-

ca desses quadros dos transtornos de personalidade para

ษ os transtornos de humor". Da mesma forma, Ehrenberg zando a "importância" de se conceber a distimia como um transtorno do eixo I, como insistem os autores do livro, subscrevendo a racionalidade do DSM, a pesquisadora nos auxilia a perceber como, por trás da patologização, reside uma estratégia de produção da eficiência. Com efeito, talvez não seja despropositado afirmar que, ao mesmo tempo em que insta o indivíduo a realizar-se constantemente em diferentes domínios da vida social, o imaginário da cultura ocidental - apreendido por nós mediante a nosologia psiquiátrica da depressão - tende a reduzir sua tolerância em relação à experiência tênue com certos sintomas que, a partir de um determinado limite estabelecido quantitativamente, são avaliados como patológicos e desvalorizados socialmente. Parafraseando um aforismo lapidar de Sahlins (2004, p. 23), diríamos que o efeito esperado, para uma sociedade que concebe a vida exclusivamente como busca de felicidade e de autorrealização, só pode ser a infelicidade e o fracasso crônicos. ${ }^{15}$ Não é difícil perceber, desde já, como a depressão, mesmo em sua forma branda e quase inofensiva, apresenta-se como problema epidêmico e grave para o imaginário sociocultural do capitalismo contemporâneo.

Mas são ainda outras categorias diagnósticas que podem fundamentar nossa assertiva, mostrando a função de captura que o DSM é capaz de exercer em relação a experiências depressivas mais cotidianas. Tais categorias se encerram na denominação "transtorno depressivo sem outra especificação", cuja correspondência, na CID-10, se dá mediante a indicação para aplicar o termo "não especificado" em diferentes categorias como "episódio depressivo", "transtorno depressivo recorrente" e "transtorno persistente do humor (afetivo)” (OMS, 1993, p. 122, 126, 128). Ampla, incerta e delegada à arbitrariedade médica, a

(1998, p. 214-215) discorre sobre o sucesso dos inibidores seletivos de recaptura de serotonina (ISRS) na administração dos sintomas duradouros da distimia.

15 É com as seguintes palavras que o antropólogo estadunidense enuncia sua sentença: "[um] povo que concebe a vida exclusivamente como busca da felicidade só pode ser cronicamente infeliz" (Sahlins, 2004, p. 23). 
terminologia permite ao clínico o diagnóstico de qualquer experiência que não satisfaça os critérios de outros transtornos depressivos, assim como envolve, de forma mais específica, diferentes categorias para as quais o Manual solicita estudos adicionais. Entre elas, destacamos o transtorno depressivo menor, o transtorno depressivo breve recorrente e o transtorno disfórico pré-menstrual.

A característica essencial do transtorno depressivo menor é a apresentação reduzida de sintomas e de prejuízo funcional em relação ao transtorno depressivo maior. Embora solicite a mesma duração de sintomas idênticos aos da lista que constitui um dos critérios diagnósticos da depressão maior, o transtorno proposto exige apenas dois sintomas depressivos, entre os quais deve constar, pelo menos, um nuclear, a saber, humor deprimido e (ou) anedonia. Diferenciando-se da categoria principal de depressão em termos de quantidade e intensidade dos sintomas, o próprio DSM-IV-TR reconhece que "[os] sintomas que satisfazem esses critérios para pesquisas para transtorno depressivo menor podem ser difíceis de diferenciar de períodos de tristeza que fazem parte da vida cotidiana " (APA, [2000] 2002, p. 726, grifo no original). ${ }^{16}$ É que, como já observamos, a lista apresenta sintomas comuns, como insônia, fadiga, dificuldade para tomar decisões, entre outros que também se destacam por sua complexidade e gravidade, como retardo psicomotor e ideação suicida. De todo modo, a existência de apenas um sintoma comum associado a humor deprimido ou a perda de interesse ou prazer em atividades cotidianas seria suficiente para o diagnóstico de transtorno depressivo menor. Daí afirmar o próprio Manual que, embora a prevalência

${ }^{16}$ Conforme as orientações estabelecidas em "diagnóstico diferencial" - em que se nota sempre a pletora de cruzamentos entre diversos transtornos mentais e a consequente dificuldade de diferenciá-los -, o clínico deve considerar normais os "períodos de tristeza". O Manual ressalva, porém, que, mesmo quando os sintomas decorrentes de tais períodos não satisfaçam os critérios diagnósticos, o clínico usufrui de liberdade para diagnosticar "transtorno depressivo sem outra especificação" (cf. APA, [2000] 2002, p. 354). desse transtorno não esteja definida, ela "pode ser relativamente comum” (APA, [2000] 2002, p. 725). Conquanto a existência do transtorno depressivo menor esteja igualmente determinada por sofrimento ou prejuízo, o documento adverte que, "em alguns indivíduos, pode haver um funcionamento quase normal”, ainda que à custa de esforço adicional significativo.

Já figurando efetivamente na CID-10 (OMS, 1993, p. 129), o transtorno depressivo breve recorrente é proposto no DSM-IV como uma variável do transtorno depressivo maior em termos de duração. Para a ocorrência do transtorno, é preciso que a mesma quantidade de sintomas depressivos da categoria principal se manifeste pelo menos dois dias, uma vez por mês, no decurso de um ano. De forma análoga ao que é indicado em transtorno depressivo menor, o Manual adverte que o indivíduo pode apresentar, nesse caso, "funcionamento próximo ao normal”, apesar do esforço acentuado que lhe pode ser igualmente solicitado.

De acordo com o DSM-IV-TR (APA, [2000] 2002, p. 721-724), o transtorno disfórico pré-menstrual se caracteriza por humor acentuadamente deprimido e ansiedade, instabilidade afetiva e desinteresse marcantes. Embora distintos, os sintomas são comparáveis aos do transtorno depressivo maior, variando em termos de duração e não de gravidade, já que pode ocorrer apenas no período pré-menstrual. Ainda que diferencie a categoria proposta da "síndrome pré-menstrual", "bem mais comum", o manual reconhece o aspecto relativamente ordinário do transtorno entre as mulheres, que encerram, de maneira geral, a maior prevalência dos transtornos depressivos. Entre as categorias propostas para estudos adicionais que destacamos, o transtorno disfórico pré-menstrual é o único que se deslocou explicitamente para a nosologia oficial do DSM-5. Note-se que, assim como a distimia, o transtorno disfórico pré-menstrual se oficializou como categoria diagnóstica apenas após experiências bem-sucedidas com antidepressivos, especificamente com o hidroclori- 
drato de fluoxetina, uma molécula produzida inicialmente para depressões brandas e moderadas (Rose, 2013, p. 293-294). Entretanto, independentemente da decisão veiculada na versão mais recente do manual, todas as categorias propostas no DSM-IV, assim como outras condutas que não satisfaçam plenamente os critérios de qualquer transtorno depressivo, podem ser diagnosticadas como "sem outra especificação", visto que uma das finalidades do DSM é, antes de tudo, orientar o clínico - que goza de absoluta liberdade graças à sua competência técnica - a partir de um paradigma relativamente consensual, porém hegemônico no campo da saúde mental e, em especial, da psiquiatria.

Como se vê, a categoria que anula a necessidade de especificação serve para capturar o que está entre transtornos definidos categoricamente. Já na introdução do DSM-IV-TR, assegura-se: "As categorias 'Sem Outra Especificação' servem para cobrir os não raros quadros que se encontram nos limites das definições específicas de cada categoria” (APA, [2000] 2002, p. 25). Daí o motivo pelo qual o DSM-5 introduz parcialmente a abordagem dimensional, assim como substitui a categoria "sem outra especificação" por outras duas que exercem, no entanto, a mesma função: "com ‡ै outra especificação" e (ou) "sem especifica`े ção”. É que, segundo o DSM-5, a abordagem categorial seria menos capaz de "capturar" a gama completa de transtornos, a qual é "virtualmente ilimitada" (APA, 2013, p. 19); apenas por isso o DSM-IV incitava a aplicação irrestrita do diagnóstico "sem outra especificação", constata o mais recente Manual. Os exemplos oferecidos pelo DSM-5 para a aplicação das duas novas denominações sugerem fortemente a permanência da função, bem como evidenciam de que forma categorias que não se deslocaram para a nosologia oficial do documento podem ser diagnosticadas na prática clínica. Entre outras especificações de que o clínico pode se valer, constam os seguintes exemplos: depressão breve recorrente, episó- dio depressivo de curta duração e episódio depressivo com sintomas insuficientes.

Embora não tenha se deslocado para a classificação oficial do DSM-5, como ocorreu com o transtorno disfórico pré-menstrual, a depressão breve recorrente é um exemplo de como o "Apêndice B: Conjunto de critérios e eixos propostos para estudos adicionais" do DSM-IV funciona efetivamente na prática clínica, a despeito do objetivo primeiro do Manual de destinar os transtornos que ali figuram tão somente à pesquisa. Inédito, o episódio depressivo de curta duração constitui, por sua vez, uma forma alternativa de diagnosticar o indivíduo que apresenta sintomas de depressão maior com duração insuficiente para tal classificação e de forma episódica, o que exclui a necessidade da recorrência que o primeiro exemplo abrange. Já o episódio depressivo com sintomas insuficientes solicita do indivíduo apenas um sintoma associado ao afeto deprimido durante duas semanas. Uma observação: tanto para esse caso como para episódio depressivo de curta duração, o DSM-5 emprega o termo "afeto deprimido" (depressed affect), diferentemente de "humor deprimido" (depressed mood), utilizado para depressão breve recorrente e todas as outras categorias diagnósticas que constam da classe de transtornos depressivos do documento. Como as sucessivas versões do Manual definem, "humor" designa clima emocional abrangente e constante, ao contrário de afeto, que é mais flutuante (APA, [1987] 1989, p. 411, 420; APA, [2000] 2002, p. 765, 770; APA, 2013, p. 817, 824). Nesse sentido, talvez seja possível interpretar "depressed affect" como uma forma atenuada do sintoma nuclear "depressed mood", o que sinaliza uma tendência a capturar e patologizar estados mais tênues, efêmeros e localizados de sofrimento. Por fim, o mais recente Manual orienta a aplicação da categoria "transtorno depressivo não especificado" quando o clínico "escolhe" (chooses) não especificar o diagnóstico (ou há informações insuficientes para tanto) diante do paciente que apresenta o critério absoluto para 
a existência de transtornos mentais: sofrimento clinicamente significativo ou prejuízo funcional em alguma área importante da vida social, familiar e produtiva (APA, 2013, p. 183-184).

Cartografada a concepção de transtornos depressivos nos manuais psiquiátricos vigentes, pode-se afirmar que um dos critérios fundamentais estabelecidos para verificar a existência de semelhantes transtornos se associa a uma essência do ethos contemporâneo. Em transtorno disfórico pré-menstrual, por exemplo, lê-se uma indicação que se repete constantemente no Manual: o transtorno “... deve ser considerado apenas quando os sintomas interferem acentuadamente no trabalho ou na escola ou em atividades sociais costumeiras e relacionamento (por exemplo, evitar atividades sociais, redução da produtividade e eficiência no trabalho ou na escola)" (APA, [2000] 2002, p. 723). Em outras palavras, diante da ausência persistente de achados laboratoriais que comprovem a efetividade de determinados transtornos mentais, como no caso da depressão, é a incapacidade social e produtiva que os caracteriza e os define segundo diferentes ordens e combinações de duração, frequência e intensidade dos sintomas. Tal critério não seria problemático em si, se não vivêssemos em uma lógica social na qual o constante aprimoramento da eficiência, da produtividade, da autorrealização e do desempenho atua como princípio normativo, restringindo, assim, cada vez, mais o que define a normalidade. Para nós, não é sem razão que a ramificação sistemática dos transtornos depressivos - que se multiplicam e variam em torno da "condição clássica” (APA, 2013, p. 155) - produz categorias que tangenciam sempre a normalidade. Para compreender a existência do ethos que se dissemina paralelamente a essa flexibilização classificatória da depressão, analisemos uma teoria central que se difundiu - tal qual o DSM - do neoliberalismo norte-americano para o mundo ocidental capitalista: o capital humano. Tal teoria, colocada progressivamente em prática desde os anos 1960, pode nos auxiliar a compreender a ideia corrente de epidemia depressiva no capitalismo contemporâneo. ${ }^{17}$

\section{CAPITAL HUMANO E TRANSTOR- NOS DEPRESSIVOS}

Sabe-se que a teoria do capital humano provém de economistas neoliberais da Escola de Chicago, entre os quais se destacam Theodore Schultz, Jacob Mincer e Gary Becker. ${ }^{18}$ Uma característica elementar de tal teoria consiste na extensão do conceito tradicional de capital ao humano, que adquire, assim, valor de mercado: daí a necessidade de o indivíduo conceber determinadas capacidades e habilidades como propriedades que devem ser não apenas mantidas como incrementadas permanentemente em vista de rendimentos futuros.

Elaborada nos anos 1960, a teoria do capital humano serve, em um primeiro momento, como modelo explicativo para a riqueza econômica da sociedade norte-americana no pós-guerra. ${ }^{19}$ Constatando que categorias centrais

${ }_{17}$ Apesar de divulgada oficialmente pela OMS em 2001, com projeção efetiva para 2020, como já assinalamos, a epidemia de depressão é uma ideia que emerge nos anos 1970 e se torna significativamente mais recorrente a partir da década de 80 (cf. Angell, 2001; Caponi, 2010; Ehrenberg, 1998, p. 119; Ehrenberg, 2004, p. 34; Hernáez, 2010, p. 117; Horwitz; Wakefield, 2008; Horwitz; Wakefield, 2010, p. 169; Kehl, 2009, p. 49; Pereira, 2011, p. 67; Pignarre, 2003, p. 19).

${ }^{18}$ Não se pretende, aqui, realizar uma análise detida e exaustiva sobre o neoliberalismo, cuja definição provém de uma diversidade de posições. Entre as mais proeminentes, destacam-se a Escola Austríaca de Economia (F. Hayek, L. Von Mises), o Ordoliberalismo alemão (W. Eucken, F. Böhm) e a Escola de Chicago, fortemente influenciada por M. Friedman. A despeito da variedade, a doutrina neoliberal compartilha pressupostos básicos, tais como a eficiência da economia de mercado e da lógica concorrencial, a constituição de um Estado frugal, a subordinação da política à economia, a austeridade fiscal e a privatização de empresas e serviços públicos estatais. Voltamo-nos essencialmente ao neoliberalismo norte-americano, dado que a laureada teoria do capital humano da Escola de Chicago tornou-se progressivamente um princípio de valores capazes de orientar a conduta dos homens nas sociedades capitalistas ocidentais (cf. López-Ruiz, 2007; Foucault 2008).

${ }^{19}$ Como mostra López-Ruiz (2007, p. 56), porém, a noção do humano como capital é anterior aos economistas teóricos da Escola de Chicago, como se observa em textos do século XVII e XIX. De todo modo, é apenas na segunda metade do século XX que o conceito será destituído de toda valoração negativa, que considerava impróprio conceber o homem como fonte de riqueza, para se tornar uma teoria econômica cuja aceitação ampla permite convertê-la em valor social. 
da economia política clássica - tais como terra, capital e tempo de trabalho - não permitiam explicar a opulência do período, economistas como Schultz propõem que o desenvolvimento e o aprimoramento de qualidades e capacidades humanas inatas ou adquiridas exercem um papel econômico fundamental. Mais tarde, o investimento em capital humano mediante níveis educacionais formais e informais se tornará o modelo explicativo da disparidade existente entre sociedades liberais avançadas e sociedades terceiro-mundistas (Foucault, 2008, p. 318-319; López-Ruiz, 2007, p. 62, 199, 220). Além de explicação econômica, a teoria do capital humano exerce ainda uma função política indispensável no contexto da Guerra Fria: trata-se de mostrar ao outro lado da cortina de ferro como certa forma de investir em educação, ciência, tecnologia e saúde constituía a supremacia do capitalismo como modelo socioeconômico (López-Ruiz, 2007, p. 61-62).

Reintroduzindo o trabalho no campo da análise econômica, os teóricos do capital humano realizam uma transfiguração da categoria de trabalhador que afeta, de modo direto e extensivo, a maneira como os homens devem conduzir suas próprias vidas. Em vez de trabalhadores assalariados que vendem aos donos dos meios de produção sua força de trabalho

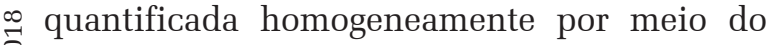
víduos devem se conceber e se conduzir indistintamente como proprietários de determinadas qualidades que lhe são próprias, heterogêneas, intangíveis e até mesmo inalienáveis, tais como a inteligência, a criatividade, a motiڤ. vação, a iniciativa individual, a persistência, a flexibilidade relacional, a comunicação, entre outras características louvadas em nossa atualidade. Associadas a competências técnicas que podem ser igualmente adquiridas mediante investimentos sistemáticos, é o conjunto dessas capacidades que determina o desempenho dos indivíduos, conforme a quantidade de capital humano acumulada. Ressalte-se que, em função da heterogeneidade do capital hu- mano, os teóricos enfrentam dificuldade tanto para quantificar o seu acúmulo real como também para calcular o retorno efetivo de investimentos que a sociedade, as instituições, as corporações, a família e os próprios indivíduos realizam no decurso da vida. De todo modo, valendo-se dos termos acurados de Foucault (2008, p. 308-316), pode-se dizer que é o acúmulo de capacidades que possivelmente torna o indivíduo uma "competência-máquina", que produzirá, assim, mais "fluxos de renda", uma vez que, para os economistas neoliberais da Escola de Chicago, o salário consiste no rendimento de um capital específico, o humano.

Tratando esquematicamente a construção teórica dos neoliberais norte-americanos, insistamos na ideia central atinente à transformação de categorias clássicas como "trabalho" e "trabalhador". Para a lógica inerente à teoria do capital humano, o trabalho se converte em capital e o trabalhador, em capitalista. É Harry G. Johnson quem explicita que o trabalhador, em uma economia industrial avançada, é tipicamente um capitalista, dado que seus próprios meios de produção, heterogêneos e intangíveis, são sistematicamente produzidos por formas permanentes de investimentos. Daí a ideia do economista da Escola de Chicago de que o trabalhador é "um meio de produção produzido" e "um item de equipamento do capital” (López-Ruiz, 2007, p. 61, 193, 220-221). Não é difícil perceber, assim, como a teoria do capital humano promove todos, indistintamente, à categoria de capitalistas de si mesmos: afinal, a administração do próprio capital humano implica saber quando, onde e como investir, tal como procedem os investidores de capital financeiro.

A partir do que designa "deslocamento conceitual valorativo”, López-Ruiz (2007) - em pesquisa que mostra a gradual disseminação da teoria do capital humano em diferentes sociedades capitalistas, incluindo aí o modo de vida de executivos de corporações transnacionais no Brasil - faz notar como a teoria do capital humano converte ainda diferentes formas 
de consumo em investimento. É que os indivíduos, para se manterem socialmente valorizados e economicamente produtivos e rentáveis, segundo a lógica concorrencial determinada pelo mercado, precisam perseguir incansavelmente o imperativo "investimento-crescimento”. Não são apenas os investimentos em educação formal - tais como escolarização, cursos profissionais e idiomáticos, especializações e programas de treinamento no trabalho - atendem tal demanda; as relações de amizade, o tempo de lazer, o tempo de afeto dedicado aos filhos, a possível constituição do equipamento genético deles mediante a escolha do parceiro conjugal adequado, até, evidentemente, o cuidado com a própria saúde constituem formas de investimento cujo efeito esperado é a rentabilidade futura. Daí a insistência de Foucault (2008), nas aulas dedicadas ao neoliberalismo norte-americano, de que a ideia fundamental da teoria do capital humano reside na extensão e na aplicação da racionalidade econômica e de mercado a todo um conjunto de fenômenos sociais e de comportamentos individuais concebidos até então como não econômicos (e.g.: criminalidade, casamento, educação de filhos, tempo de afeto). Através dessa "economização" de todo o tecido social, ${ }^{20}$ a economia se torna "programação estratégica da atividade dos indivíduos" (Foucault, 2008, p. 307). Desse modo, é o mercado, como regulador geral da sociedade, que define o consumo como investimento ou não. ${ }^{21}$

Progressivamente, constitui-se, assim, a

${ }^{20}$ Como se sabe, para a doutrina neoliberal, tal "economização" não se restringe apenas ao corpo social, mas se estende ainda ao corpo político, à arte de governar, dado que a economia de mercado deve restringir a ação governamental, reduzindo o Estado a um mínimo necessário. A despeito das diferenças, desde o liberalismo clássico de Adam Smith até o neoliberalismo alemão e norte-americano, postula-se a subordinação da racionalidade política à racionalidade econômica.

${ }^{21}$ López-Ruiz (2007, p. 224) mostra como a ordem normativa e valorativa imposta pelo mercado determina qual consumo será concebido como investimento: por exemplo, segundo a perspectiva do mundo corporativo, cursos de inglês ou de espanhol podem ser considerados investimentos, ao passo que o aprendizado de línguas como o tupi e o francês não apenas não constituem uma forma de investimento como ainda manifestam uma problemática dispersão de interesses. nova ética do homo oeconomicus contemporâneo. Ao contrário do modelo clássico, que se caracterizava principalmente por relações de troca em uma sociedade mercantil, o homo oeconomicus contemporâneo não apenas aplica a racionalidade econômica a todas as relações como assume a forma empresa como um modo de existência que orienta sua relação com o trabalho, com a propriedade privada, com o casamento, com a família, com seu grupo, com o tempo, com o futuro e, sobretudo, consigo próprio. Para Foucault (2008, p. 203, 331-332), se o homo oeconomicus retorna dessa maneira, é porque a multiplicação da forma empresa no tecido social inteiro constitui o escopo da política neoliberal. Nos termos do filósofo, em vez de uma "sociedade supermercado", regulada pela troca mercantil, o neoliberalismo funda uma "sociedade empresarial", que torna a dinâmica concorrencial de mercado o impulso vital das instituições e corporações tanto quanto dos indivíduos propriamente ditos.

Tal ética empresarial, que caracteriza a economia social de mercado própria do ordoliberalismo alemão, é radicalizada pelos neoliberais norte-americanos. Por isso, tanto para Foucault (2008, p. 301-302) quanto para López-Ruiz (2007), o neoliberalismo norte-americano constitui toda uma forma de ser, de pensar e de agir; ${ }^{22}$ ou seja, por meio da teoria do capital humano, essa vertente do neoliberalismo institui o ethos característico do homo oeconomicus atual, que é tornar-se empreendedor de si mesmo, o que está igualmente no cerne da nova cultura psicológica abordada pelo sociólogo francês Robert Castel (2011). ${ }^{23}$ Na qualidade de empresa múltipla e contínua, o indivíduo deve perseguir o autoinvestimento

${ }^{22}$ Nesse sentido, Foucault (2008, p. 301-302, 423) sustenta que, em vez de uma técnica de governantes sobre governados, o neoliberalismo é uma relação entre eles: donde a definição de que a governamentalidade neoliberal consiste na arte de governar a partir da racionalidade dos próprios governados.

${ }^{23}$ Ver especialmente o prefácio à reedição de La gestion des risques, escrito por Castel (2011) trinta anos depois da publicação de seu livro, cujo objetivo consistia em capturar tendências do capitalismo contemporâneo em relação à cultura psicológica emergente. 
e a formação permanente como os meios que o modulam adequadamente para o mercado, não se esquecendo, porém, que é o próprio mercado que determina o valor de tais meios. Não é à toa que termos como "formação permanente" e "modulação" são empregados precisamente por Deleuze (1992, p. 219-226), em seu célebre texto prognóstico, no qual relaciona a noção de "sociedades de controle" ao espraiamento social da forma empresa, que substitui a função da família e da escola, instalando-se no coração do humano. É que, diferentemente de procedimentos disciplinares que "moldavam" os indivíduos em instituições, a noção - "terrível”, no entender de Deleuze (1992, p. 216) de "formação permanente" os "modula" para o mercado, essa entidade abstrata e universal do capitalismo, que produz, fantástica e concretamente, riqueza e miséria. Daí a necessidade política de se questionar para que os jovens solicitam, insistentemente, motivação, estágios e formação permanente. ${ }^{24}$ Portanto, ao contrário da suposta liberdade humanista, que a forma mais sofisticada e avançada do capitalismo pretende promover, assiste-se a uma nova servidão voluntária: ainda que os investimentos se dobrem sobre os próprios indivíduos, é em função do mercado que o acúmulo de capital humano deve ser programado, executado e mobilizado. É dessa maneira que a racionaliN. dade governamental do neoliberalismo reduz e \& une todas as dimensões da vida dos indivíduos e seus diferentes modos de existência à esfera econômica do mercado. Para Boccara (2013), antropólogo pesquisador do multiculturalismo neoliberal, essa é a base do neoliberalismo "di$\dot{2}$ ferencialista”, em suas variadas formas e con$\stackrel{\infty}{\infty}$ textos. de que a vida se reduz, em nossos dias, à pró-

${ }^{24}$ É com as seguintes palavras que Deleuze (1992, p. 226) - conclui seu texto de 1990: "Muitos jovens pedem estranhamente para serem 'motivados', e solicitam novos está-

gios e formação permanente; cabe a eles descobrir a que estão sendo levados a servir, assim como seus antecessores descobriram, não sem dor, a finalidade das disciplinas. Os anéis de uma serpente são ainda mais complicados que os buracos de uma toupeira”. pria carreira, tornando ambas indiscerníveis tanto em países desenvolvidos quanto em desenvolvimento (López-Ruiz, 2007; Stroud, 2014). ${ }^{25}$ Tal atributo parece ser o efeito de uma teoria econômica incorporada gradativamente por doutrinas da administração no decurso dos anos 1990 e difundida por todo o tecido social como uma forma moralmente correta e economicamente conveniente de conduzir a vida. Para nosso propósito, um aspecto relevante desse percurso demonstrado por López-Ruiz (2007) a respeito da teoria do capital humano reside na função política adquirida por uma verdade científica. Se, em um primeiro momento, a teoria pretendia apenas explicar cientificamente a riqueza da sociedade norte-americana no pós-guerra, ela logo se converte em um conjunto de princípios, valores e crenças que orienta a conduta dos homens. ${ }^{26} \mathrm{Coe}-$ rente, a tese do sociólogo se apresenta inequivocamente: a partir de uma teoria econômica e científica, constitui-se uma ética social que caracteriza o atual espírito do capitalismo. É por isso que a teoria do capital humano não interessa em si mesma, mas apenas na medida em que embasa a maneira como o indivíduo racionaliza sua relação com o mundo, com os outros e consigo. ${ }^{27}$

No centro da concepção empresarial

${ }^{25}$ Evidenciada por pesquisas acadêmicas, tal ideia é amplamente disseminada por veículos de comunicação de massa. No Brasil, por exemplo, ela se expressa, de modo preciso e inequívoco, na revista Você $S / A$, título de vasta circulação nacional, que se volta para o mundo dos negócios e manifesta, explícita e compactamente, a ideia de que o indivíduo é sua própria empresa. Sobre a revista e o empreendedorismo disseminado amplamente como valor social, ver López-Ruiz (2007, p. 250-262).

${ }^{26}$ Sublinhe-se que o modo de vida de executivos de corporações transnacionais constitui o objeto da pesquisa sociológica de López-Ruiz (2007) na medida em que o ethos dessas personagens representa, de forma emblemática, o paradigma da vida social contemporânea.

${ }^{27}$ Com ponderação, López-Ruiz (2007, p. 306) ressalva que a teoria do capital humano constitui apenas um elemento do capitalismo contemporâneo, cujas formas concretas são, evidentemente, particulares no conjunto das sociedades ocidentais. A centralidade da teoria do capital humano reside, contudo, no fato de que tal formulação teórica implica um conjunto prescritivo de valores que orientam sobremaneira o modo como os indivíduos tendem a conduzir suas vidas. Nos termos de Foucault (2008), a teoria do capital humano atua como princípio de governamentalidade, cuja função, nesse caso, consiste em programar a vida dos indivíduos conforme as exigências do mercado. 
da vida, encontra-se a noção de desempenho. Passível de determinação mediante a quantidade de capital humano acumulado, o desempenho funciona atualmente como medida do sucesso e do fracasso dos indivíduos em uma sociedade que se compõe, pois, de "vencedores" e de "perdedores". ${ }^{28}$ Tanto é assim que, no campo específico da nosologia psiquiátrica da depressão, a ausência ou a disfunção na capacidade de desempenho se apresenta como um critério fundamental para verificar a existência de transtornos depressivos, cuja sintomatologia envolve efetivamente a fadiga, a lentidão psicomotora, a dificuldade comunicacional, a ausência de energia, de motivação, de prazer, de expectativa e de projetos futuros, entre outros déficits. É nesse sentido que a epidemia depressiva pode ser a expressão mais acabada de uma legião de "fracassados" que não suportam a responsabilidade inscrita na ideia de autorrealização constante, que está no cerne da biopolítica da saúde mental. ${ }^{29}$ Se o excesso é constitutivo da dinâmica neoliberal - como Santos (2007, p. 11-13, 21) mostra a partir da atualização da ópera Don Giovanni por Michael Haneke -, a depressão, como déficit, insuficiência e desvalorização da vida, se apresenta logicamente como um problema que inviabiliza a manutenção, a aquisição e o exercício do capital humano. Ou seja, para a lógica neoliberal predominante nas sociedades capitalistas ocidentais contemporâneas, a depressão é puro desinvestimento individual e coletivo, ainda que outros mercados se beneficiem com ela, nomeadamente a indústria farmacêutica e as técnicas terapêuticas diversas. ${ }^{30}$ Desde o

${ }^{28}$ Insistamos na ideia de que o fracasso no mundo corporativo equivale ao fracasso pessoal absoluto. A partir de $O$ Relatório Lugano, de Susan George, Santos (2003, p. 25-27) destaca o fato de que o neoliberalismo destrói o ambiente e produz perdedores em escalas inauditas. Mais terrificantes são os critérios seletivos que constituem o grupo dos perdedores, que precisam reconhecer-se como responsáveis pela incompetência, inaptidão, pobreza, ignorância, preguiça, criminalidade etc. que lhe são próprias, segundo os preceitos neoliberais.

29 Sobre a biopolítica da saúde mental, ver Corbanezi (2015, p. 83-104).

${ }^{30}$ Mostrando o aumento do consumo de psicotrópicos, Rose (2013, p. 290) indica que os transtornos mentais podem ser uma oportunidade fundamental para a criação de déficit de neurotransmissores até a extenuação energética em todos os níveis, a depressão representa, em seus variados graus, a impossibilidade de realização da saúde otimizada que se depreende de discursos institucionais e médicos. Invertendo os sinais, não soa estranho observar que o "episódio hipomaníaco", embora solicite atenção psiquiátrica, seja apresentado tacitamente no DSM-IV-TR como um estado quase socialmente desejado, uma vez que "[a] alteração no funcionamento em alguns indivíduos pode assumir a forma de um aumento acentuado na eficiência, realizações ou criatividade" (APA, [2000] 2002, p. 362). O problema é que essa acentuação patológica da eficácia e das capacidades também pode causar algum prejuízo social ou ocupacional, bem como indicar o desenvolvimento da euforia descontrolada e possivelmente psicótica, típica do episódio maníaco propriamente dito. ${ }^{31}$

Dada a relevância da noção de desempenho, tecnologias médicas contemporâneas se convertem em tecnologias de otimização, cujo objetivo primordial não é mais apenas curar doenças, mas aperfeiçoar as capacidades dos indivíduos. Ainda que restritas às democracias liberais avançadas - isto é, ao "ocidente rico" 32 -, tais tecnologias constituem atualmente o que Rose (2013) designa como "a política da própria vida” (the politics of life itself). Para o sociólogo inglês, o problema da biomedicina

lucro privado e para o crescimento econômico nacional. Considerando, porém, o argumento dos economistas da Escola de Chicago de que o capital humano constitui o elemento principal do desenvolvimento econômico dos países, não se pode recusar que a depressão, como desinvestimento individual do ponto de vista da produtividade pragmática de mercado, representa um obstáculo lógico para preceitos neoliberais.

${ }^{31}$ Nesse sentido, problematizando a depressão como sintoma social do mal-estar contemporâneo, Kehl (2009, p. 31,50 ) argumenta que a epidemia atual do transtorno encontra suas condiçỗes de possibilidade em uma sociedade simultaneamente antidepressiva e maníaca, que “... aposta na euforia como valor agregado".

${ }^{32}$ Rose (2013, p. 353) observa que, em vez do desenvolvimento de tecnologias médicas sofisticadas - tais como medicina genômica e neurogenética -, políticas primordiais como de saneamento básico seriam suficientes para salvar muitas vidas em países terceiro-mundistas. Não obstante a relevância vital da afirmação, o próprio sociólogo inglês mostra, em suas pesquisas, a necessidade de se investigarem as tendências de países desenvolvidos, de modo a detectar em que direção o capitalismo avança. 
molecular, em nossos dias, não consiste especialmente em normalizar e restituir a saúde; trata-se, antes, de superar barreiras biológicas, intervir em condições pré-sintomáticas e aperfeiçoar capacidades como força, resistência, longevidade, atenção, inteligência: é o que se observa desde o uso variado da genética até o consumo plástico de psicofármacos.

Com efeito, entre outras formas de investir em capital humano - tais como escolarização, cursos idiomáticos e profissionalizantes, treinamento on-the-job, atenção médica, ingestão de vitaminas, aquisição de informação sobre o sistema econômico -, pode-se incluir o consumo de psicofármacos. Sem pretender discutir a polêmica se o medicamento seria capaz de produzir um novo self - o que parece pouco provável -, o fato incontestável é que seu uso pode estimular capacidades, se não inexistentes, ao menos latentes. Nesse sentido, o uso cosmético de antidepressivos, segundo a fórmula popularizada pelo psiquiatra estadunidense Peter Kramer, constituiria um direito dos indivíduos em sociedades democráticas liberais, em que todos supostamente gozam de liberdade para produzir bem-estar e para otimizar suas capacidades, tornando-se better than well. Autor de Listening to Prozac: a psychiatrist explores antidepressants drugs and the - remaking of the self, Kramer (1993) sustenta ก que o uso de antidepressivos serve tanto para aliviar os sintomas do transtorno quanto para criar condições para que as pessoas realizem com sucesso suas atividades, produzindo e otimizando, por conseguinte, o bem-estar. É por isso que, para Ehrenberg (1998, p. 203), segundo o qual a depressão é uma doença da insuficiência da capacidade de ação e de iniciativa, a pílula promovida pelo best-seller do psiquiatra estadunidense pretende mais estimular a ação do que produzir a felicidade, como as traduções francesa e brasileira do título da obra dão a entender equivocadamente. ${ }^{33}$ Ora, em vez

${ }^{33}$ A saber: Prozac: le bonheur sur ordonnance?, Paris: First, 1994, e Ouvindo o Prozac: uma abordagem profunda e esclarecedora sobre a "Pílula da Felicidade", Rio de Janeiro: Record, 1994. de condenar ingenuamente o uso pragmático e utilitário circunscrito à ideia de psicofarmacologia cosmética, é preciso perceber sua coerência absoluta no contexto da biopolítica da saúde mental, que inculca, nos indivíduos, a necessidade tanto de realização permanente quanto de bem-estar como fórmula para o sucesso social.

Como se vê, o argumento de Kramer não destoa do imaginário da cultura ocidental contemporânea, para o qual "sentir-se bem" implica realizar-se como profissional, pai, cônjuge e cidadão capaz de contribuir efetiva e resignadamente com a sociedade tal como nos é apresentada. Acentuada, essa lógica sugere que a saúde não equivale mais apenas à vida no silêncio dos órgãos, como postulava o fisiologista René Leriche (Canguilhem, 2002, p. 67-76); para além dessa definição, a saúde consiste, hoje, numa configuração ativa a ser percebida e solicitada insistentemente. Com esse raciocínio, St-Hilaire (2009) mostra, de forma convincente, como o uso cosmético e plástico de antidepressivos - outrora designados "energizantes psíquicos" - permite ajustar os indivíduos às demandas sociais contemporâneas, ao mesmo tempo em que as evidencia. Mais do que conspiração de uns sobre os outros, trata-se do atual processo de constituição da subjetividade em sociedade. ${ }^{34}$ Nesse sentido, o discurso da saúde, segundo o sociólogo, constitui "o lugar pelo qual se ordenam as exigências sociais". E o que assistimos hoje é ao "... aprimoramento de nossas capacidades, um melhor ajustamento às exigências da vida à qual aspiramos ...” (St-Hilaire, 2009).

A centralidade da noção de desempenho permite perceber que, para além do sofrimento indescritível da depressão severa, tal como testemunha o escritor Willian Styron (1991), a "epidemia" do transtorno é instaurada por ${ }^{34}$ Nesse sentido, St-Hilaire (2009), pesquisador da ação social dos medicamentos, assegura que o encontro da biomedicina com as tecnociências produz tecnologias eficazes para transformar a subjetividade mediante soluções moleculares. É o que se passa com antidepressivos, que agem especificamente no cérebro, em vez de abranger o indivíduo em sua totalidade, como era até pouco tempo sob o paradigma da psicologia expresso no DSM I e II. 
outro temor: o da crise de incapacidade ${ }^{35}-$ sabe-se, afinal, que a monstruosidade para o capitalismo consiste na improdutividade. Próximo ao aspecto sociológico da tese de Kehl (2009), ${ }^{36}$ Ehrenberg (1998) já sustentara que o aumento dos casos de depressão resultava da conquista de autonomia dos indivíduos após os movimentos contestatórios do final dos anos 1960. Para o sociólogo francês, em vez do modelo disciplinar - no qual a permissão ou a interdição estabelecidas pela lei constituem o fundamento do conflito psíquico próprio da concepção freudiana das neuroses -, os indivíduos experimentam, desde então, a autonomia como norma social inédita que lhes solicita, sem limites, a capacidade de ação, a iniciativa individual, a escolha pelo modo de vida e a responsabilidade. É por isso que, para o autor de La fatigue d'être soi, a depressão consiste, antes de tudo, numa patologia da insuficiência, típica de uma sociedade que atribui ao indivíduo, exclusivamente, a responsabilidade pelo sucesso social. ${ }^{37}$ Daí a ideia de Ehrenberg (1998, p. 129, 236) de que tudo se passa atualmente como se assistíssemos à ascensão do indivíduo soberano de Nietzsche: porém, em vez de um modo de vida selecionado e destinado a alguns "fortes", segundo a tipologia nietzscheana, tal indivíduo sobrevém democraticamente massificado. ${ }^{38}$ Em que pese o as-

${ }^{35}$ Cabe observar, nesse sentido, que o termo incapacidade não resulta de um dado natural absoluto, mas pode ser, ele também, socialmente construído, como sustenta a perspectiva do construcionismo social (cf. Conrad; Barker, 2011, p. 194).

${ }^{36}$ Subtraindo a discussão psicanalítica que foge ao nosso escopo, deve-se destacar que o aspecto sociológico da tese de Maria Rita Kehl (2009) é que a depressão recusa e questiona valores essenciais das sociedades capitalistas contemporâneas, entre os quais sobressaem a velocidade e o gozo, isto é, a aceleração do tempo e o imperativo da felicidade, do prazer e da satisfação "prêt-à-porter".

${ }^{37}$ Lançando mão da tese de Ehrenberg, Safatle (2012) sustenta que o aumento do sofrimento psíquico característico da depressão resulta da atual mudança do paradigma produtivo, que solicita dos indivíduos atributos antes restritos ao paradigma de produção estética e os quais constituíam, paradoxalmente, a crítica ao taylorismo, a saber: criatividade, capacidade para enfrentar riscos, flexibilidade, mobilidade, afetividade, conjugados, evidentemente, com iniciativa individual e responsabilidade.

${ }^{38}$ Em Sociedade do cansaço, o sul-coreano Byung-Chul Han (2017) critica - com razão, a nosso ver — a ideia do sociólogo francês de que assistimos hoje à ascensão do in- pecto controverso da associação do indivíduo contemporâneo ao além-do-homem nietzscheano, é preciso reter a ideia fundamental do sociólogo francês de que o transtorno depressivo deve ser percebido especialmente em termos de incapacidade de ação, ou seja, a depressão é menos paixão triste do que ação insuficiente. ${ }^{39}$

\section{CONSIDERAÇÕES FINAIS}

Sublinhada a dimensão capital de parâmetros normativos como desempenho, autorrealização, ação e performance, pode-se afirmar que a ideia de epidemia depressiva não resulta da alta incidência efetiva de casos severos. De fato, como Horwitz e Wakefield (2010, p. 248-249) mostram, o discurso institucional da OMS contribui para a fabricação da epidemia depressiva, aplicando o nível de gravidade de depressão a todos os casos indistintamente; desse modo, cumpre-se o objetivo de advertir a relevância do transtorno psiquiátrico como problema de saúde pública. Procedendo assim, asseguram ainda os pesquisadores norte-americanos, a OMS exerce o significativo papel de divulgar para todo o mundo, e de modo inquestionável, a concepção hegemônica da Associação Psiquiátrica Americana. ${ }^{40}$

Dado o lugar central que a saúde - e, especialmente, a saúde mental - ocupa no regime ético contemporâneo, pode-se afirmar que a ideia de epidemia depressiva encontra

divíduo soberano de Nietzsche. Como observa Han (2017. p. 94-95), ao contrário do sujeito contemporâneo performático e hiperativo, o além-do-homem nietzscheano é um espírito-livre, forjado como contramodelo de crítica cultural desse sujeito esgotado, que dissemina uma singular ausência de espírito (Corbanezi, 2018, no prelo).

${ }^{39}$ É igualmente como "patologia da ação" que os psicanalistas franceses Pierre Fédida (1999, p. 15-35) e Pierre-Henri Castel (2009, p. 137-173) abordam a depressão.

${ }^{40}$ Com efeito, no Relatório sobre a saúde no Mundo 2001 (OMS, 2001, p. 48), dedicado à saúde mental, lê-se um elogio à padronização e à confiabilidade diagnóstica, ambas estabelecidas pela racionalidade psiquiátrica desde o DSM-III. Desse modo, torna-se possível realizar o objetivo da psiquiatria transcultural de universalizar a concepção ocidental de depressão. Para Pignarre (2003, p. 38-39), o etnocentrismo psiquiátrico, que institui diagnósticos padronizados, mas não necessariamente válidos, constitui elemento fundamental para a transformação da depressão em epidemia mundial. 
suas condições de possibilidade no contexto da biopolítica da saúde mental, exercendo, ela própria, função política equivalente. É que, alertando os indivíduos para a necessidade de cuidado diante de um futuro sombrio, otimizam-se, natural e consequentemente, suas potencialidades ${ }^{41}$ Assim, uma sinergia política se constitui a partir de duas verdades científicas díspares: a concepção psiquiátrica dos transtornos depressivos e a teoria econômica do capital humano. Não obstante a tendência da natureza humana a desenvolver-se e aperfeiçoar-se, em tempos de capitalismo cognitivo, de economia imaterial, de sociedades de controle ou de biopolítica, é fundamental perguntar por que verdades e técnicas científicas e pretensamente neutras toleram, cada vez menos, sintomas tênues de sofrimentos cotidianos.

A análise minuciosa de como são descritos e apresentados os transtornos depressivos em manuais psiquiátricos contemporâneos dá a ver que a altíssima incidência da depressão pode relacionar-se também à laxidão de critérios diagnósticos e sua consequente patologização de sofrimentos mais brandos. Como vimos, os transtornos depressivos menos graves - ou seja, aqueles que gravitam em torno da condição nuclear, que é o transtorno depressivo maior - sempre tangenciam a normalidade, $\stackrel{\infty}{\sim}$ restringindo-a, assim, a parâmetros mais rígi. dos e normativos de desempenho, o qual, sucomo critério diagnóstico ante a ausência de dados laboratoriais definitivos. Uma relação inequívoca se depreende dessa afirmação: um dos critérios fundamentais para constatar a efetividade de transtornos depressivos é precisamente o mesmo que o capitalismo, em suas formas neoliberais predominantes, exige insistentemente dos indivíduos. Se, por um lado, é preciso investir em si, como apregoa a disse-

光 ${ }^{41}$ A relevância da saúde no regime ético contemporâneo transforma o paciente - passivo por definição - em sujeito

I ativo, constituindo indivíduos que são verdadeiros econo-

ช mistas de sua própria saúde, segundo a expressão de Rose

(2013, p. 140). Considerada a exigência ética atual de que se pode sempre adquirir mais saúde, o fato de não possuí-la intensifica o sofrimento do indivíduo, supostamente ษ responsável por sua condição patológica. minada teoria do capital humano, por outro, a definição do transtorno se dá mediante a incapacidade de fazê-lo.

Anunciada desde os anos 1970, a ideia de epidemia depressiva parece tomar forma na medida em que a racionalidade científica e classificatória da psiquiatria se desenvolve, capturando cada vez mais condutas levemente incapacitadas, tristes e menos produtivas. Em outras palavras, a progressiva ramificação e a flexibilização dos critérios diagnósticos da depressão permitem que se territorializem condutas heterogêneas e singulares - com combinações diversas de sintomas relativamente banais e cotidianos - no lugar comum da classificação formal. Não se trata, com tal afirmação, de recusar, de forma inconsequente, a dimensão real da depressão como patologia que causa sofrimento, tampouco de negligenciar os aspectos biológicos e psíquicos que a envolvem. Queremos chamar a atenção para o fato de que a produção e o estabelecimento de diversos subtipos de depressão se relacionam diretamente ao déficit de atributos e de disposições que o atual espírito do capitalismo valoriza e solicita dos indivíduos.

Não há dúvida de que, em relação à biopolítica da saúde mental - que incita os indivíduos à realização constante de suas potencialidades intelectuais, emocionais e laborais -, a depressão é fundamentalmente antinormativa: ao mesmo tempo em que é expressão do corpo indisciplinado (incapacitado, desenergizado, lento), desregula a homeostase populacional (improdutividade, custos, suicídio) e recusa, assim, palavras-chave de nossa época (motivação, comunicação, mobilidade, criatividade, velocidade, eficiência). É quando relacionada ao ethos contemporâneo predominante que a depressão parece tornar-se um problema gravíssimo: talvez não seja apenas o suposto déficit de neurotransmissores que cause o sofrimento, mas a impossibilidade de realizar valores e princípios que orientam o modo de vida dos indivíduos nas sociedades capitalistas contemporâneas. Associada sinergicamen- 
te ao modo de vida preconizado e disseminado pela teoria econômica do capital humano, a flexibilização classificatória da depressão não apenas contribui para a fabricação da epidemia depressiva como restringe a normalidade a padrões mais rígidos de desempenho, correspondendo, assim, à estratégia biopolítica da saúde mental, cuja função atual consiste - não de forma exclusiva - em otimizar as capacidades dos indivíduos.

Embora seja difícil recusar que a racionalidade psiquiátrica se desenvolva pari passu com as tendências neoliberais das sociedades capitalistas ocidentais, seria precipitado pretender estabelecer uma relação de causalidade direta e absoluta, como se a racionalidade econômica capitalista determinasse exclusivamente a nosologia psiquiátrica ocidental da depressão. Não obstante essa ponderação, não é totalmente digressivo notar que, mesmo para Weber (2004, p. 165) - que demonstra cautela na relação de causalidade entre o ascetismo protestante e o espírito do capitalismo, empregando, para tanto, a expressão conceitual "afinidade eletiva” -, o poderoso cosmos da ordem econômica moderna se relaciona diretamente ao desenvolvimento do cosmos científico, determinando, assim, o estilo de vida dos indivíduos. Em todo caso, em vez de pretender denunciar pura e simplesmente o aspecto capitalístico dessa medicina científica ocidental, procuramos evidenciar a subjetivação (leia-se: modo de produção de existências) que se estabelece a partir da relação entre discursos médicos, institucionais, científicos e econômicos. E, nesse sentido, parece-nos que tanto o discurso positivo da saúde mental quanto o estabelecimento científico dos diversos subtipos de depressão podem contribuir para que o indivíduo se incline à autoexploração própria do homo oeconomicus atual: incorporando e naturalizando o discurso empreendedor, todos devem indistintamente produzir uma saúde otimizada, cuja consequência inevitável é a realização de potencialidades, capacidades e performances que assegurariam rentabilidade e empregabilidade futuras. É fato que, em todo espectro da vida social, assistimos à produção de um modo de vida assentado na realização individual. No entanto, diferentemente de um "cuidado de si", que se dobra sobre o sujeito como autodeterminação e relação consigo, que resiste a códigos e poderes específicos, o cuidado exacerbado de nossos dias - um a mais de saúde - parece circunscrever-se majoritariamente às demandas do mercado.

Recebido para publicação em 30 de junho de 2016 Aceito em 11 de junho de 2018

\section{REFERÊNCIAS}

AMERICAN PSYCHIATRIC ASSOCIATION (APA). Diagnostic and statistical manual of mental disorders (DSM-I). 1st Edition. Washington: APA, 1952.

Diagnostic and statistical manual of mental disorders (DSM-II). 2nd Edition. Washington: APA, 1968.

Diagnostic and statistical manual of mental disorders (DSM-III). 3rd Edition. Washington: APA, 1980.

Manual de diagnóstico e estatística de distúrbios mentais (DSM-III-R). [1987]. São Paulo: Manole, 1989.

Manual Diagnóstico e Estatístico de Transtornos Mentais (DSM-IV. [1994]. Porto Alegre: Artmed, 2000.

Manual Diagnóstico e Estatístico de Transtornos Mentais (DSM-IV-TR). 4 ${ }^{\mathrm{a}}$ Edição [2000]. Porto Alegre: Artmed, 2002.

Diagnostic and statistical manual of mental disorders (DSM-5). 5th Edition. Washington: APA, 2013.

ANGELL, M. A epidemia de doença mental. Revista Piauí, São Paulo, n. 59, ago. 2011. Disponível em http:// revistapiaui.estadao.com.br/edicao-59/questoes-medicofarmacologicas/a-epidemia-de-doenca-mental. Acesso em: 29.08.2011.

ASSIS, J. M. Machado de. O Alienista. In: . Obra Completa. Rio de Janeiro: Nova Aguilar, 2006. v. 2, p. 253-288.

BOCCARA, G. Geoffroy de Lagasnerie, la dernière leçon de Michel Foucault: sur le néolibéralisme, la théorie et la politique. In : Nuevo Mundo Mundos Nuevos. Paris, 2013. Disponível em http://nuevomundo.revues.org/65544. Acesso em: 30.08.2014.

BROMET, E. et al. Cross-national epidemiology of DSMIV major depressive episode. BMC Medicine, Londres, v. 9, 2011. Disponível em http://www.biomedcentral. com/1741-7015/9/90. Acesso em: 14.09.2015.

CANGUILHEM, G. O Normal e o patológico. Rio de Janeiro: Forense Universitária, 2002.

CAPONI, S. O diagnóstico de depressão, a "petite biologie" e os modos de subjetivação. In: et al. (Orgs.) Medicalização da vida: ética, saúde pública e indústria farmacêutica. Palhoça: Ed. Unisul, 2010. p. 135-143.

CASTEL, P. L'esprit malade: cerveaux, folies, individus. Paris: Les Éditions d'Ithaque, 2009. 
CASTEL, R. La gestion des risques: de l'anti-psychiatrie à l'après-psychanalyse. Paris: Les Éditions de Minuit, 2011.

CONRAD, P.; BARKER, K. K. A construção social da doença: insights-chave e implicações para políticas de saúde. Idéias, Campinas, n. 3, p. 185-220, 2011.

CORBANEZI, E. R. Saúde mental e depressão: a função política de concepções científicas contemporâneas. 2015. 169 p. Tese (Doutorado em Sociologia) - Programa de Pós-Graduação em Sociologia da Universidade Estadual de Campinas.

Sociedade do cansaço: uma constatação irrefutável. São Paulo: Tempo Social, USSP, 2018 [no prelo].

DELEUZE, G. Conversações. São Paulo: Ed.34, 1992.

DUNKER, C. O sequestro da neurose. In: Revista Cult, Dossiê: O poder da psiquiatria, São Paulo, p. 32-37, out. 2013.

EHRENBERG, A. La fatigue d'être soi: dépression et société. Paris: Éditions Odile Jacob, 1998.

. La dépression. Naissance d'une maladie. L’Histoire, Amsterdam, n. 285, p. 34-36, 2004.

FÉDIDA, P. Dos benefícios da depressão: elogio da psicoterapia. São Paulo: Escuta, 2002.

FÉDIDA, P. O agir depressivo. In: Paulo: Editora Escuta, 1999. p. 15-35. . Depressão. São

FOUCAULT, M. Nascimento da Biopolítica: curso dado no Collège de France (1978-1979). São Paulo: Martins Fontes, 2008.

FRANCES, A. Normal Grief vs Depression in DSM-5. Psychology Today, New York, Mar. 2010. Disponível em https://www.psychologytoday.com/blog/dsm5-indistress/201003/normal-grief-vs-depression-in-dsm5. Acesso em: 10.08.2014.

Don't confuse grief with depression. Huffpost Science, [s.1], Jan. 2012a. Disponível em http://www. huffingtonpost.com/allen-frances/dont-confuse-griefwith-d b_1233883.html. Acesso em: 11.08.2014.

. DSM 5 Is Guide Not Bible - Ignore Its Ten Worst Changes. Psychology Today, New York, Dec. 2012b. Disponível em https://www.psychologytoday.com/blog/ dsm5-in-distress/201212/dsm-5-is-guide-not-bible-ignoreits-ten-worst-changes. Acesso em: 12.08.2014.

. Last plea to DSM-5: save grief from the drug companies. Psychology Today, New York, Jan. 2013. Disponível em https://www.psychologytoday.com/blog/ $\infty$ dsm5-in-distress/201301/last-plea-dsm-5-save-grief-theণิ drug-companies. Acesso em: 13.08.2014.

@ FREUD, S. Luto e melancolia. São Paulo: Cosac Naify, 2011.

GORI, R. Le sujet de la santé mentale: de l'actualité de Foucault. In: ARTIÉRES, P. et al. (Orgs.) Cahiers de L'Herne - Foucault. Paris: Éditions de L'Herne, 2011. p. 312-317.

กิ ถึ HAN, B. Sociedade do cansaço. 2 $2^{\mathrm{a}}$ Edição ampliada. ' Petrópolis, RJ: Vozes, 2017.

HENNING, M. F. Neuroquímica da vida cotidiana. 2. Cadernos IPUB, Rio de Janeiro, v.6, n. 18, p. 123-131, 2000.

$\infty$

HERNÁEZ, Á. M. A medicalização dos estados de ânimo.

¿ O consumo de antidepressivos e as novas biopolíticas

$\approx$ das aflições. In: CAPONI, S. et al. (Orgs.) Medicalização

- da vida: ética, saúde pública e indústria farmacêutica.

Palhoça: Ed. Unisul, 2010. p. 111-134.

Pr

HORWITZ, A. V.; WAKEFIELD, J. C. A tristeza perdida: como a psiquiatria transformou a depressão em moda. São ๙ Paulo: Summus, 2010.

Is There Really an Epidemic of Depression? Scientific American, New York, 2008. Disponível em http:// www.scientificamerican.com/article/really-an-epidemic-ofdepression/. Acesso em: 15.07. 2014.

INSEL, T. Transforming Diagnosis. Apr. 2013. Disponível em http://www.nimh.nih.gov/about/director/2013/transformingdiagnosis.shtm. Acesso em: 10.11.2013.

KEHL, M. R. O tempo e o cão: a atualidade das depressões. São Paulo: Boitempo, 2009.

KRAMER, P. Listening to Prozac: a psychiatrist explores antidepressants drugs and the remaking of the self. New York: Viking Press, 1993.

LÓPEZ-RUIZ, O. Os executivos das transnacionais e o espírito do capitalismo: capital humano e empreendedorismo como valores sociais. Rio de Janeiro: Azougue Editorial, 2007.

MARCUS, M. et al. Depression: a global public health concern. WHO Department of Mental Health and Substance Abuse, 2012. Disponível em http://www.who. int/mental_health/management/depression/who_paper depression_wfmh_2012.pdf. Acesso em: 30.07.2015.

MORENO, R. A. et al. Distimia: do mau humor ao mal do humor: diagnóstico e tratamento. $3^{\mathrm{a}}$ Edição. Porto Alegre: Artmed, 2010.

ORGANIZAÇÃO MUNDIAL DA SAÚDE (OMS). Classificação de transtornos mentais e de comportamento da CID-10: descrições clínicas e diretrizes diagnósticas. Porto Alegre: Artmed, 1993.

ORGANIZACÃO MUNDIAL DA SAÚDE (OMS). Relatório sobre a saúde no mundo 2001: saúde mental: nova concepção, nova esperança. Biblioteca da OMS, 2001.

PEREIRA, L. O trabalho em causa na "epidemia depressiva”. Tempo Social, São Paulo, v. 23, n. 1, p. 67-95, 2011.

PEREIRA, M. E. C. O DSM e a crise da psiquiatria. In: Revista Cult, Dossiê: O poder da psiquiatria, São Paulo, p. 38-45, out. 2013.

PIGNARRE, P. La depresión: una epidemia de nuestro tiempo. Barcelona: Debate, 2003.

ROSE, N. A política da própria vida: biomedicina, poder e subjetividade no século XXI. São Paulo: Paulus, 2013.

SAFATLE, V. Perto demais da redenção: depressão, flexibilidade e fim da ética do trabalho. In: NOVAES, A. (Org.) Mutações: elogio à preguiça. São Paulo: Edições SESC SP, 2012. p. 385-404.

SAHLINS, M. Esperando Foucault, ainda. São Paulo: Cosac Naify, 2004.

SANTOS, L. G. A informação após a virada cibernética. In: et al. Revolução tecnológica, internet e socialismo. São Paulo: Editora Fundação Perseu Abramo, 2003. p. 9-33.

Apresentação. In: LÓPEZ-RUIZ, O. Os executivos das transnacionais e o espírito do capitalismo: capital humano e empreendedorismo como valores sociais. Rio de Janeiro: Azougue Editorial, 2007. p. 11-21.

SERPA JÚNIOR, O. D. Mal-estar na natureza: um estudo crítico sobre o reducionismo e o determinismo biológico em psiquiatria. 1997. 281p. Tese (Doutorado em Psiquiatria), Programa de Pós-Graduação do Instituto de Psiquiatria da Universidade Federal do Rio de Janeiro.

ST-HILAIRE, P. L. De l'usage plastique des antidépresseurs: un révélateur des figures de l'individu contemporain. In: Esprit Critique, Revue Internacionale de Sociologie et des Sciences sociales. Pays de la Loire, v.12, n.1, 2009. Disponível em http://www.espritcritique.fr/dossiers/p?t03code $=118 \&$ varti cle=esp1201article12\&vrep=1201. Acesso em: 15.12.2014.

STROUD, B. Pessoas estão mais ricas, mas vida hoje é mais pobre, diz filósofo (entrevista). Folha de São Paulo, Caderno Mercado. São Paulo, 09 dez. 2014.

STYRON, W. Perto das trevas. Rio de Janeiro: Rocco, 1991. WEBER, M. A ética protestante e o "espírito" do capitalismo. São Paulo: Companhia das Letras, 2004. 


\section{DEPRESSIVE DISORDERS AND CONTEMPORARY CAPITALISM}

\author{
Elton Corbanezi
}

This article aims to show how the evolution of psychiatric nosology of depression may to relate to certain requirements of contemporary capitalism. First, we investigate the conceptions of depressive disorders from the third edition of Diagnostic and Statistical Manuals of Mental Disorders (DSM), which established the current psychiatric paradigm, focusing especially on the last two versions (DSM-IV and DSM-5). Along with International Classification of Diseases by WHO, the recent editions of manual are the main classification systems of psychiatry, guiding clinical practice and conceptually basing the current idea of depressive epidemic. Then we show how the economic theory of human capital, developed by neoliberal economists of the Chicago School, becomes a social value that, widely accepted and disseminated, guides the conduct of life of individuals in advanced liberal societies and in Third World societies. Therefore, we affirm that the systematic ramification and flexibility of depressive disorders, which establish as pathological subtle forms of suffering, correspond to logic of intensification of performance of certain individual capacities indispensable to contemporary capitalism.

KEYwORDS: Depressive disorders. Contemporary capitalism. Human capital. Conduct of life. Depressive epidemic.

\section{TROUBLES DÉPRESSIFS ET CAPITALISME CONTEMPORAIN}

\section{Elton Corbanezi}

Cet article a pour but de montrer comment l'évolution de la nosologie psychiatrique de la dépression peut se rapporter à certaines exigences du capitalisme contemporain. D'abord, nous étudions les conceptions de troubles dépressifs depuis la troisième édition du Manuel Diagnostique et Statistique des Troubles Mentaux (DSM), qui a établi le paradigme psychiatrique actuel, en nous concentrant surtout sur les deux dernières versions (DSM-IV et DSM-5). À côté de la Classification Internationale des Maladies de l’OMS, les éditions les plus récentes du manuel sont les principaux systèmes de classification de la psychiatrie, en orientant la pratique clinique et en fondant conceptuellement l'idée actuelle de l'épidémie dépressive. Ensuite, nous faisons voir comment la théorie économique du capital humain, développée par des économistes néolibéraux de l'École de Chicago, devient une valeur sociale, qui, acceptée et diffusée largement, guide la conduite de vie des individus dans les sociétés libérales avancées et dans les sociétés tiers-mundistes. Nous soutenons, ainsi, que la ramification et l'assouplissement systématiques des troubles dépressifs, qui établissent comme pathologique des formes subtiles de souffrance, correspondent à la logique d'intensification de la performance des certaines capacités individuelles indispensables au capitalisme contemporain.

Mots-CLÉs: Troubles dépressifs. Capitalisme contemporain. Capital humain. Conduite de vie. Epidémie dépressive.

Elton Corbanezi - Doutor em Sociologia. Professor do Departamento de Sociologia e Ciência Política e do Programa de Pós-Graduação em Sociologia da Universidade Federal de Mato Grosso. Atualmente exerce o cargo de Chefe de Departamento. Integra, como pesquisador, o grupo de pesquisa Conhecimento, Tecnologia e Mercado (CTeMe - IFCH/Unicamp), desenvolvendo pesquisas na área de sociologia em relação aos seguintes temas: ciência, cultura, psiquiatria, saúde mental, depressão, subjetividade e biopolítica. Suas mais recentes publicações são: Sociedade do cansaço: uma constatação irrefutável. Tempo Social, USP, São Paulo [no prelo]; O terror do positivo: o alienista e o positivismo comteano. Plural, USP, São Paulo, v. 22, p. 209-232, 2015; Geoffroy de Lagasnerie: uma polêmica leitura neoliberal de Foucault. Revista Brasileira de Ciências Sociais (RBCS), v. 29, p. 195 
